\title{
Health Systems in Latin America: Principal Components of Attention
}

\section{Cristina Gomes}

Facultad Latinoamericana de Ciencias Sociales, FLACSO Mexico, Population and Develpment, Mexico City, Mexico

Email: cristinagomesmx@gmail.com

How to cite this paper: Gomes, C. (2019) Health Systems in Latin America: Principal Components of Attention. Health, 11, 1299 1319.

https://doi.org/10.4236/health.2019.1110100

Received: September 6, 2019

Accepted: October 13, 2019

Published: October 16, 2019

Copyright ( 2019 by author(s) and Scientific Research Publishing Inc. This work is licensed under the Creative Commons Attribution International License (CC BY 4.0).

http://creativecommons.org/licenses/by/4.0/

\begin{abstract}
This article discusses the evolution of healthcare systems in Latin American countries, their origins and main characteristics and sources of financing, coverage and the availability of services and human resources from the Donabedian perspective, which also considers indicators of behaviors and preferences and social values underlying healthcare in different societies. The method adopted is the estimation of correlations and principal components to explore how health expenditures, poverty and inequalities are associated with healthcare indicators such as life expectancy, immunizations, treatments offered by health systems in transmissible and chronic diseases, considering indirect indicators of patient's behaviors and preferences, as well as social values and cultural diversity in Latin American societies. The results show that the expansion and actual availability of immunization, treatments against transmissible diseases and hospital beds are the main criteria responsible for the results in healthcare and increase in life expectancy; the availability of health services is an important component for secondary level of care and allows the population to be committed to positive behaviors in a context of poverty and inequalities, with disadvantages for indigenous people.
\end{abstract}

\section{Keywords}

Healthcare, Poverty, Inequalities, Latin America, Indigenous

\section{Introduction}

Healthcare systems in Latin America originated in the early twentieth century. Initially corporate insurance was created by workers in sectors such as industry, commerce, banking, and public service, among others. In these corporate institutions of mutualism, workers and employers both contributed to ensuring that healthcare was available to staff. On the other hand, philanthropic institutions, 
and later the state, offered health services to the poor.

This fragmented character of the healthcare systems remains well-established today in the majority of the countries-citizens with formal contracts have total health coverage with access to all the levels of complexity, from primary to tertiary services and treatments, while the poor receive only limited coverage in prevention, access and treatments. Fragmentation in health systems contributes to social inequalities in the region - the most unequal in the world.

In the 1940-1950s, the national states assumed responsibility for both health protection and attention, and health ministries were created in all the region's countries to provide vaccinations, preventive action and basic care, without achieving universal coverage [1] [2]. In the 1970s health systems experienced increasing costs around the world, due to the rapid development of the healthcare market, the inflationary prices of new products and technologies, and a growing and uncontrollable demand. Increases in spending on healthcare generated a reallocation of state financing for this sector, even in developed countries with universal Welfare States. Sustainability became uncertain in Europe and also in Latin America, where universal healthcare coverage had never been a reality. Public investment in the health sector was reduced even more in the years of economic crisis.

In the 1980s, different reforms in constitutions, legislation and in health systems were carried out through changes in management decentralization, competition between providers with the participation of the private sector, regulation and monitoring by independent agencies, and restrictions in public officials' positions in planning and managing health systems.

Until the 1990s, the majority of the Latin American population was assisted by the Ministries of Health that, according to the law, were obliged to offer most preventive services, including immunization, basic healthcare and disease control, and mainly for the poor, informal workers, among other vulnerable groups.

Despite the effort to extend coverage through law reforms, at the end of the 1980s it was still estimated that there were 130 million poor Latin American citizens with access to health systems [3]. The coverage of contributory Social Security covered the majority of the population in Costa Rica (85\%) and Panama (55\%), countries in which the Ministry of Health only financed health care for a minority of the population. However, in Peru, Colombia, Ecuador, Dominican Republic and other countries, the contributory Social Security only covered a small percentage of the population $(24 \%, 18 \%, 11 \%$ and $9 \%$, respectively) and, as a result, the Ministry of Health had to cover almost the entire population in terms of prevention and attention to health, which implied huge investments in the public health sector.

Likewise, public expenses did not correspond to the unequal needs for coverage of high proportions of the population. For example, in Colombia, the State devoted $38 \%$ of its resources to $82 \%$ of the population (being served by the Ministry of Health), and invested $62 \%$ of the health sector resources to only $18 \%$ of 
the population, which was affiliated to the contributive social security system [3]. Therefore, in the Latin American countries with the largest proportions of poor and unskilled citizens, this largest part of the population, with higher mortality and mobility rates, received the lowest investment in health.

In Costa Rica, health insurance also covered affiliated domestic and rural workers, peasants, the self-employed, micro and macro entrepreneurs, unpaid workers and pensioners. The Uruguayan health insurance did not cover the latter groups and, in Peru, farmers, unpaid workers and employees of large companies were excluded from health insurance. In the Dominican Republic, the public sector covered micro-entrepreneurs. In Mexico there was voluntary insurance but-in practice-it wasn't used by the majority of the population [3].

Facing this persistent exclusion of the poorer groups, in the 1990s new reforms were put in place to cut spending and bureaucracy, and to promote new financing mechanisms and costs recovery, competence, private participation and the social control of public health management systems in the region.

Efforts were concentrated in universalizing maternal and infant health. Ecuador approved a law in 1994, a solidarity fund in 1998, and an integral plan in 2002 and Bolivia created maternity and child insurance in 1996 and a law in 2002. Peru approved a basic health program in 1994, a health and nutrition program in 1997, and maternity and child insurance in 1999. Argentina approved a solidarity redistribution fund in 1993 and Mexico created a health program in 1989, popular insurance in 1992, and a general law in 2003. In 1982, Chile created private plans, but they covered only $18.5 \%$ of the population, and the old public system covered $67.5 \%$ [4].

Colombia reformed its health system in 1993 [5] combining public financing, managing and regulation with private participation and three affiliation arrangements; a contributory scheme that included self-employed, a subsidized scheme for the poor and a regime of affiliates in the public sector. The new system increased coverage to $57 \%$ of the population in 2002 but financial transfers generated crises in hospitals.

In Brazil the corporate institutes were unified in 1966, and in 1977 the State was converted into a buyer of services from the private sector, favoring corruption, particularly in the tertiary sector. In 1988, the constitution approved a unified system that provided universal access to the decentralized health system. Municipalities are the main providers of services and Health Councils were created in 1990 to promote participation [6].

In summary, changes in health systems have been relatively homogeneous across the region and, starting $21^{\text {st }}$ Century, almost all countries had very fragmented models at different levels nowadays.

The great majority of reforms have been made within the legal and normative framework, finding alternative forms of public-private partnership and management. Private sector participation in different modalities has increased, and also the costs, in scenarios where lack of State resources for financing the health 
sector increases participation in a country's GDP; this is a highly inflationary sector.

Reference [7] identifies as common trends in the reforms of Chile, Brazil and Colombia the decentralization of healthcare to municipalities, the evolution to a public-private plurality in which the public sector bureaucracy has power over the entire system, and fragmented complementary, private and corporative subsystems over the relationships and negotiations between lenders and service providers. Fragmentation, public-private partnership, increasing inflationary costs, and decentralization are factors of instability and crisis in financing, managing and evaluating these systems. Consequently, tensions are recurrent between the decentralization processes based on an "insurance base" and "local participation" aimed at guaranteeing access and improvements to services. Beyond these conflicts, it is expected that reforms could be an opportunity to deepen democracy in the region, including the poor as beneficiaries of these systems and increasing their capacity for empowerment through their participation in decision-making mechanisms.

From the 2000s most of the countries in the region achieved coverage for their entire population, even though under differing financing schemes and unequal conditions for the poor to access them-contributory schemes (based on the labor market insertion), subsidized schemes (based on income and complemented by subsidies from the State), and schemes based in the Ministry of Health (totally subsidized by the State). Contributory schemes cover more than $50 \%$ of the population in Costa Rica, Uruguay and Argentina. Subsidized schemes cover more than $50 \%$ of the population in Chile and Colombia, and resources from the Ministry of Health (also subsidized) are predominant in Guatemala; Mexico and Peru who have a similar percentage of financing sources from contributory, subsidized and Ministry of Health schemes for each group of population-formal workers and their families, subsidized for people who share the finance with subsidies from the State, and fully subsidized healthcare from the Ministry of Health. Brazil has a universal system that doesn't specify the diverse federal sources of resources, and attends the whole population equally, independent of their labor market insertion or level of income [8].

\section{Inequalities in Health and Social Justice}

There is a need-especially for the groups excluded from health systems (which are basically poor people, and of indigenous ethnic groups and afro-descendants) - to establish guidelines to ensure their inclusion and the service's quality, as this could quickly impact poorly sensitive indicators of access, use and quality of attention. Funding, coverage, quality and equality seem to follow the more up-to-date health systems in the region.

Health systems are based on norms, services and human resources available, and management mechanisms that are used to evaluate the results and quality of their actions and results. According to References [9] [10] the quality of health- 
care depends on three components: 1) the physical environment, including infrastructure, material and human resources available (e.g. hospital beds and doctors), and also actual availability and performance (comparing the actual conditions to the ideal or the best you can expect to attain; 2) the technological and scientific bases (the coexistence of western and non-western bases of knowledge and attention (e.g. the presence of indigenous medicine in the countries); and 3) the characteristics, behaviors and preferences of the patients. Biological characteristics, for example, are the exposure to infectious pathogens (vaccines), behaviors are related to how the patients accept and follow medical recommendations and treatment regimens, and preferences means what the societies value, such as attachment to life, fear of death, willingness to take risks (accidents and violence), and what societies consider useful or dominant in their lifestyles (diet, diabetes, hypertension). All these factors are oriented by the social objectives of health systems, conceptualized as efficiency in the allocation of resources and equity by the values of social justice in each society [11] [12] (Table 1).

Table 1. Donabedian's theoretical-conceptual framework and indicators of provision and quality of health services.

\begin{tabular}{|c|c|c|c|}
\hline Perspective & Concept & Components & Indicator of Inequality \\
\hline \multirow[t]{2}{*}{ Social base } & \multirow{2}{*}{$\begin{array}{l}\text { Material wealth and } \\
\text { standard of living }\end{array}$} & Poverty & Poverty headcount ratio at $\$ 1.90$ a day (2011 PPP) 2012-2017 \\
\hline & & Health expenses & Health expenses as \% of the GNP 2017 \\
\hline $\begin{array}{l}\text { Values cultural } \\
\text { diversity }\end{array}$ & $\begin{array}{l}\text { Technological \& } \\
\text { scientific base }\end{array}$ & $\begin{array}{l}\text { Coexistence of western and non } \\
\text { western systems Indigenous cultures }\end{array}$ & Indigenous people as a $\%$ in the population $2010-17$ \\
\hline \multirow{2}{*}{$\begin{array}{l}\text { Material and human } \\
\text { resources }\end{array}$} & Material resources & Availability of bed in hospitals & Number of hospital beds per 10 thousand inhabitants 2017 \\
\hline & Human resources & Number of doctors & Number of physicians per 1 thousand inhabitants 2013-2016 \\
\hline \multirow{9}{*}{$\begin{array}{l}\text { Patients } \\
\text { characteristics, } \\
\text { behaviors and } \\
\text { preferences }\end{array}$} & \multirow[t]{4}{*}{$\begin{array}{l}\text { Biological } \\
\text { characteristics }\end{array}$} & \multirow[t]{4}{*}{ Immunology Vaccines } & $\begin{array}{l}\text { Immunization against Tuberculosis-BCG (per 100,000 } \\
\text { inhabitants) } 2017\end{array}$ \\
\hline & & & $\begin{array}{l}\text { Immunization against Measles (\% of children ages } 12-23 \\
\text { months) } 2017\end{array}$ \\
\hline & & & $\begin{array}{l}\text { Immunization against Poliomyelitis (\% among } 1 \text {-year-old) } \\
2016\end{array}$ \\
\hline & & & $\begin{array}{l}\text { Immunization against Diphtheria, pertussis and } \\
\text { tetanus-DPT (\% of children } 12 \text { - } 23 \text { months) } 2017\end{array}$ \\
\hline & \multirow[t]{4}{*}{ Behaviors } & Diet: Salt consumption & Average level of blood pressure in the population 2016 \\
\hline & & Diet: Carbohydrates consumption & Diabetes prevalence (\% of population ages 20 to 79) 2017 \\
\hline & & Effectiveness following BK treatment & Tuberculosis treatment success rate (\% of new cases) 2016 \\
\hline & & Adhesion to preventive care & $\begin{array}{l}\text { Causes of death by communicable diseases and maternal, } \\
\text { prenatal and nutrition condition (\% of total) } 2016\end{array}$ \\
\hline & Preferences & Taking risks, attachment to life & $\begin{array}{l}\text { Intentional homicides (per 100,000 people) } 2016 \\
\text { Cause of death by injury (\% of total) } 2016\end{array}$ \\
\hline
\end{tabular}




\section{Context of Coverage and Inequalities in Health in Latin American Countries}

The Fragmented systems reinforce inequalities in health, and all aspects of healthcare provision. That is why References [9] [10] [11] suggests analyzing the quality and performance of health systems comparing actual observation in each country to the ideal situation, e.g. the minimum standards of coverage established by the WHO in terms of hospital beds or doctors available to attend the population. Another way to establish an ideal norm is to compare national data with the average of Latin America, as a minimum to achieve in all the countries.

The availability of infrastructure and human resources includes the set of services unit facilities, materials and equipment, health service workers (doctors, nurses, and technical personnel), and medicines. This article analyzes two indicators for which there is a higher coverage of data-the number of hospital beds per 10,000 inhabitants and the number of doctors per 1000 inhabitants in each country.

Regarding material infrastructure, the number of hospital beds is one indicator of availability of tertiary attention that is registered in administrative records, at least in the public sector. In Europe there are 63 hospital beds per 10,000 inhabitants, compared to 10 in the African Region [13]. In Latin America, some countries are under or similar to the African average: 6 hospital beds per 10,000 inhabitants in Guatemala, 7 in Haiti, 8 in Honduras and Venezuela, 9 in Nicaragua, 11 in Bolivia, 12 in Costa Rica, and 13 in El Salvador and Paraguay. A second group has around 15 - 16 hospital beds per 10,000 people: Colombia, Ecuador, the Dominican Republic, Peru and Mexico. A third group has around 21 - 28 hospital beds per 10,000 inhabitants (Chile, Brazil, Panama, and Uruguay). Only Argentina (50) and Cuba (52) are at the highest levels, and closer to Europe's figures.

Human resources are usually expressed as the number of qualified healthcare personal per 10,000 inhabitants. The WHO considers having fewer than 23 healthcare professionals (including doctors, nurses and midwives) for every 10,000 inhabitants insufficient to provide adequate attention [14]. Considering just physicians, there are 13 doctors for every 10,000 inhabitants worldwide, with large variations between countries and regions-from 2 doctors per 10,000 inhabitants in Africa to 32 in Europe and 19 doctors in the Americas [12]. The Latin American average, at 2.07, was much lower in 2012 and most of the countries do not even produce or publish this data. The few Latin American countries with available information are mostly below the African average. In 2013-2016, the average was 0.47 physicians per 1000 inhabitants in Jamaica, 0.9 in Nicaragua, 1.2 in Costa Rica, 1.6 in Panama, 1.8 in Colombia, and 1.9 in Brazil. Only three countries recorded higher than Africa's average, but were still very distant from the European average-Mexico (2.2), Argentina (3.9) and Cuba (7.5) [15].

On the demand side, patients interact with services and healthcare personnel, and are also responsible for health achievements since their characteristics, be- 
haviors and preferences play an important role in adhering to and successfully following the recommendations and treatments offered by health services.

The patients' biological characteristics depend on previous exposure to infectious pathogens, through the immunization received from health services. This article focuses on the immunization coverage for the vaccines for which data is available in Latin American countries (Measles-containing-vaccine firstdose (MCV1), Polio (POL3) among 1-year-olds (\%) and Diphtheria Tetanus toxoid and Pertussis (DTP3).

Measles first-dose has the highest coverage, and varies from $85 \%$ in the Dominican Republic and Paraguay, $86 \%$ in Ecuador and Guatemala, $88 \%$ in Peru and Venezuela, $90 \%$ in El Salvador and Argentina, up to 93\% in Chile, Colombia and Costa Rica. The highest coverage is in Bolivia (94\%), Brazil, Jamaica, Panama and Uruguay (95\%), Mexico (96\%), Honduras (97\%) and Cuba and Nicaragua (99\%).

DPT3 coverage is $80 \%$ in Guatemala, $83 \%, 84 \%$ and $85 \%$ respectively in Ecuador, Venezuela and Panama, $87 \%$ in Bolivia, $89 \%$ in Brazil, from $91 \%$ to $95 \%$ in Colombia, Argentina, Paraguay, El Salvador, Chile and Uruguay, and $97 \%$ to 99\% in Honduras, Mexico and Costa Rica, Nicaragua, Cuba and Jamaica.

Polio immunization has a lower coverage than Measles first-dose and DPT3. Its coverage varies from $45 \%$ in Haiti, $72 \%$ in Brazil, $79 \%$ in Ecuador, $82 \%$ in Guatemala and Venezuela, 91\% in Colombia, 93\% in Paraguay, 95\% in Uruguay, 96\% in Mexico, 97\% in Honduras and Costa Rica, 98\% in Cuba, and 99\% in Jamaica.

Patients' behaviors are related to the interaction between medical recommendations and the attitudes and practices of patients, or how they accept and follow treatment regimens and recommendations in order to achieve success in curing the ailment. One available indicator to measure this compatible behavior is the success in treating tuberculosis, which involves the patient's response to the doctor's recommended treatment. "Treatment success rate" corresponds to the percentage of new cases cured. The lowest rate of cure is in Jamaica (23\%), Argentina (44\%), Paraguay (57\%), Chile (61\%), and Brazil (62\%)

The number of cases of tuberculosis treated in health services varies greatly in the region: from 18 in Jamaica, 44 in Argentina, 49 in Ecuador, 52 in Bolivia, 53 in the Dominican Republic, 54 in Chile, 60 in Colombia and Haiti, 61 in Paraguay, 62 in Brazil, 64 in Mexico, 66 in Panama and Venezuela, 67 in Uruguay, 68 in Costa Rica, 69 in Honduras, 70 in Nicaragua and Peru, 72 in Cuba, and 74 in El Salvador.

Patient's preferences mean what they value, such as attachment to life, fear of death, taking risks (accidents and violence, deaths), and what they consider useful and adopt as dominant lifestyles. An indicator of the willingness to take risks would be the rates of accidents and violence (such as homicide rates) and the proportion of deaths caused by injuries would be a proxy to risky behavior.

Homicides rates are higher in El Salvador (82.8 per 100,000 people), Venezuela (56.6), Honduras (56.5), Jamaica (47), Brazil (29.5), Colombia (25.5) and 
Mexico (19.6). However, considering the percentage of injuries in the total causes of death, the highest violent causes of death are observed in Honduras (19.6\%), Venezuela (19.2\%), Guatemala (15.7\%) and Bolivia (13.1\%), Ecuador (12.8\%), Nicaragua (12.7\%), Haiti (2.6\%), and Brazil (12.2\%).

Finally, the social objectives in healthcare involve equity and a sense of social justice, with some level of redistribution in the assignment of budgets. Latin America is the most unequal region in the World, and also the most culturally diverse.

Traditional social indicators based on income are poverty rates and the Gini index. Poverty has been halved in the last 20 years in the region, but inequalities have shown very small changes. In 2017, Honduras was already at the top, with $19.3 \%$, followed by Guatemala with $8.9 \%$ of the total population living on less than USD 1.90 per capita per day. All the other countries have less than $6 \%$ of the population living in extreme poverty. The Gini index shows a different behavior when comparing poverty-it is highest in Brazil (53.3), Paraguay (52.4), Honduras (50.1), Panama (49.9), Colombia (49.7), and Guatemala and Costa Rica both have 48.3 .

Considering cultural diversity, indigenous people correspond to $41 \%$ of the total population in Bolivia and Guatemala. In Peru this proportion is 26\%, followed by Mexico (15\%), Panamá (12.2\%), Honduras (7.2\%) and Ecuador (7\%). Indigenous populations experience exclusion in public services in general, and particularly in health. The difference in accessing health services when comparing the access of indigenous people and non-indigenous is an indicator of the exclusion of the more vulnerable groups. This difference is highest in Panamá (52\%), Colombia (36\%), El Salvador (26\%), Brazil (21\%), Nicaragua (20\%), Bolivia and Peru (19\%), and Costa Rica (18\%).

Beyond exclusion, the presence of a high number or proportion of indigenous groups in the population also represents the coexistence of different cultural and technical backgrounds and values in health. In most Latin American countries western and non-western values on healthcare, perceptions, and practices in medicine coexist. According to References [9] [10] [11], healthcare has more than just a technical base since there are social objectives to the distribution and the allocation of resources and attention in order to guarantee equity, based on a principle of justice or impartiality. Even in countries with low resources, the combination of technical conditions and social values can allow the achievement of better results, considering the levels available.

However, inequalities and exclusion are obstacles to equity, and the poor, indigenous and afro-descendent people (who are the main beneficiaries of these systems), should develop their capacity for empowerment through their participation in decision-making mechanisms.

For groups excluded from health systems (which are basically poor people, and indigenous and other ethnic groups) there is a particular need to establish guidelines to ensure their inclusion with quality services, which could quickly 
impact poorly sensitive indicators of access, use and quality of healthcare, due to maternal and infant mortality, hypertension, diabetes, transmissible diseases and other more common demands at the primary level of attention. These indicators contrast the main trends in epidemiological transition in Latin America since transmissible diseases have decreased as a percentage in the total number of causes of death and causes of morbidity, while the percentage of chronic diseases has increased-in particular, cardiovascular disease-which is the leading cause of death in the region. Hypertension is the predominant risk factor for this disease [16].

Beyond the health indicators, inequalities and empowerment form the background to the inefficiency of resources allocation in Latin America. To achieve efficiency, redistribution and improvement in universal wellbeing and, in particular, in healthcare depends on limited resources, but also on the predominant principles of justice or impartiality in using these limited resources, which vary among societies. However, even with limited resources, it should be possible to improve health, decrease inequalities and accomplish the priorities based on the relationship between cost and effectiveness.

In this article the indicators of inequality in the societies analyzed are the Gini index, and the percentage of the population living on under USD 1.90 per day, adjusted by Purchasing Power Parity (PPP 2011) to represent poverty levels. The percentage of indigenous people in the total population is a proxy to the predominant condition of poverty and discrimination experienced by this group.

The level of healthcare expenses in the GDP indicates the investment made by the State to provide health prevention and attention, and the level of out of pocket expenses made by families indicates to what extent families finance the gaps in public health expenses to cover their real needs.

\section{Methods}

The main questions of this research are "what are the relationships between inequalities, budget and the results in health?" and "how do the huge presence of indigenous people, and poverty and inequality correlate to health conditions?".

To answer these questions, data from twenty-one Latin American countries were analyzed using component analysis methods to analyze a set of indicators, based on the Donabedian's perspective of the provision and quality of health systems, and also on poverty, inequalities and multicultural indicators.

The countries selected in the sample were all the countries from Central and South America. Only Jamaica from the Caribbean is included, due to the availability of information.

Information from each domain was taken from the 2012-2017 World Bank Database [14] and from the 2016 WHO database and documents [12] [13]. Some indicators had to be excluded due to the data being incomplete for most of the countries, such as the proportion of indigenous population attended to by health services. 
To analyze so many domains, the correlations matrix and principal components analyses are useful; the former to analyze bivariate between pairs of variables and to explore if variables are highly correlated or independent, and the latter to transform the original set of variables into a smaller set of uncorrelated variables representing most of the information of the original data set. The reduction of the number and the identification of the main variables make it easier to understand the problem analyzed, and to simplify and impose some structure on the domain, which retains most of the information from the original framework. First of all, the matrix of correlations between each pair of variables was analyzed, in order to explore if there would be some groups of association, and in order to support the analysis of the results of the principal components. The goal of principal components is to explain part of the variation in a set of observed variables on the basis of a few underlying dimensions. However, principal components analysis has no underlying statistical model of the observed variables and focuses on explaining the total variation in the observed variables on the basis of the maximum variance properties of principal components. Geometrically, the first principal component is the line of closest fit to the $\mathrm{n}$ observations in the $\mathrm{p}$ dimensional variable space, and it minimizes the sum of the squared distances of the $\mathrm{n}$ observation from the line in the variable space representing the first component. The second component is a line to fit to the residuals from the first principal component, and the first three components define a three-dimensional plane of closest fit [17].

\section{Results}

\subsection{Correlation Matrix}

The correlation matrix indicates that there are some highly correlated variables and others that are not. The highest correlations are observed in the domain of immunizations against DPT, tuberculosis, poliomyelitis and hepatitis (Table 2).

As expected, all the variables of this domain of immunizations are highly negatively correlated to the percent of deaths by transmissible, maternal and child mortality and nutrition, and also with immunization against tuberculosis. These indicators are in the domain of preventive causes of illness and death, possible to be reduced with low resources and universal coverage, with high cost-effective interventions and leading to successful results. In fact, these indicators were relevant for achieving increases in life expectancy in the region in the last 50 years, and continue to be so and for the epidemiological transition, that means precisely the reduction in the rates of deaths caused by transmissible diseases and increasing in causes related to the higher survival and aging around the world.

A second group in the level of correlations' coefficient is the coverage of pregnant women with adequate antenatal care (at least 4 visits) - positively associated with the control of blood pressure and pneumonia, or basic attention to health, which represents a protective behavior. This result reflects the expansion observed in coverage of basic services since the 1980s, the main achievement in 


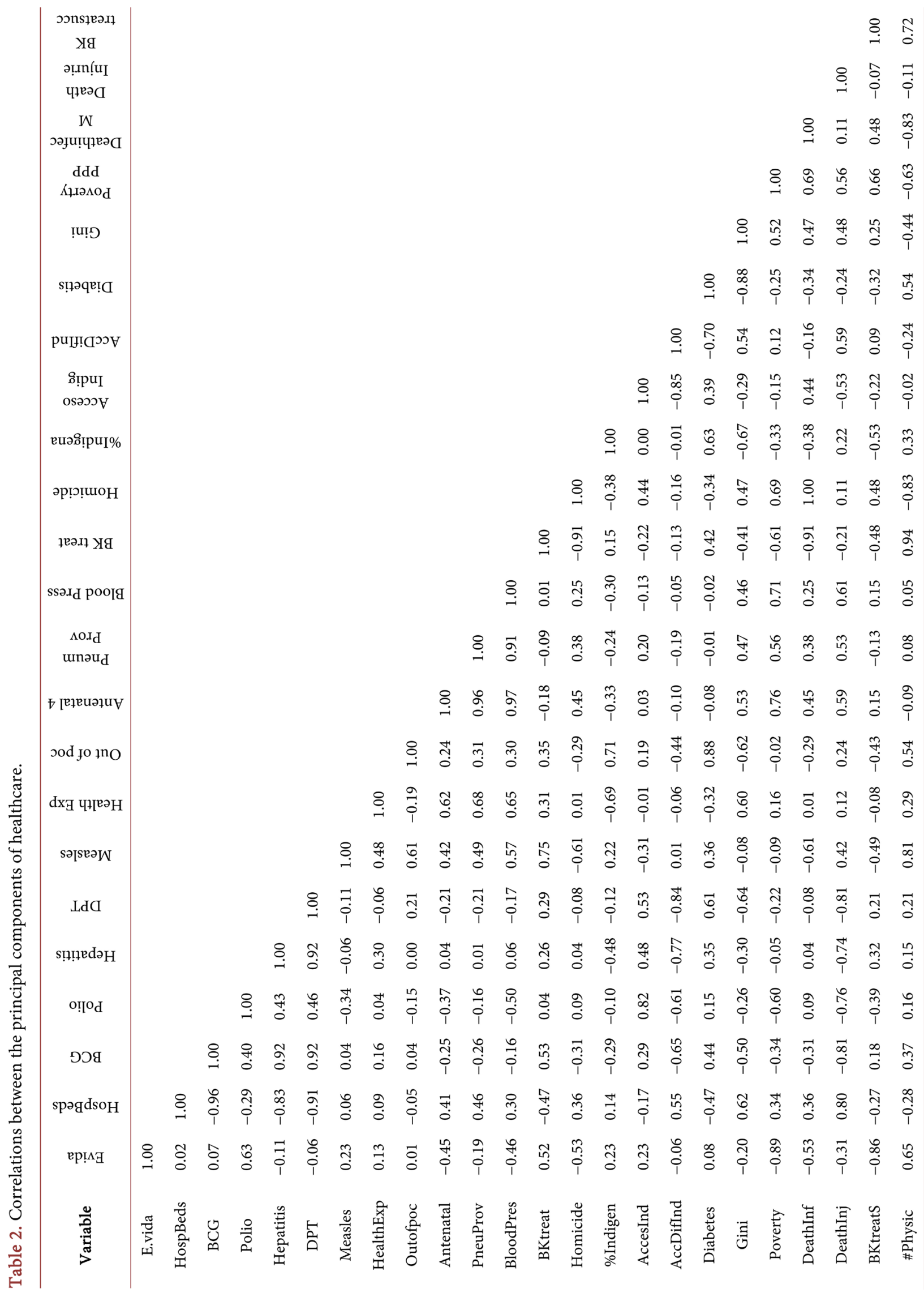


the region, and the adherence of the population to this strategy.

A third group of high correlations includes the negative correlation between the number of hospital beds per 10,000 inhabitants and the high value of out of pocket expenses from the families in order to finance health treatments. The higher the availability of hospital beds, the lower the out of pocket income spend by families, mainly in a scenario in which the region has increased the coverage for almost all the groups of the population. This group includes also positive correlations between the number of hospital beds per 10,000 inhabitants and the number of physicians per 10,000 inhabitants and rates of death by injuries, with negative association with the expenses of the families-out of pocket expenses for healthcare, as well as positive correlations between the rates of death by injuries and the rates of homicides in societies.

This third group is in the domain of tertiary attention in health in association to the social base of violence in Latin America, that implies higher costs and that is the main weakness of the health systems in Latin America, since their effectiveness depends more on the effectiveness of the availability of expensive services and specialized doctors, as well as an efficient system of reference and counter-reference. Moreover, this domain demonstrates the relevance of the increases in causes of hospitalization and deaths due to violent causes, related to the risk life-styles and the lack of security in Latin America, with reflects in healthcare, in particular in the tertiary attention. Once the majority of the countries have overcome the first phase of demographic and epidemiologic transitions, in which infections have been mostly controlled and prevented, chronic diseases and their complications as well as violence gain relevance among causes of death and hospitalization.

There are also moderate positive correlations between immunization against poliomyelitis and the rates of deaths by transmissible diseases, maternal, child and nutrition causes of deaths, and life expectancy is correlated with the proportion of indigenous people in the total population.

The indicators without moderate or strong correlation with others are the rates of diabetes and the rates of success of treatment of new cases of tuberculosis.

The most relevant result is the positive correlations between the proportion of indigenous in the population and the out of pocket costs of healthcare for families. However, there aren't the same correlations between the costs of health care with poverty or inequalities. This result reinforces the lower access and higher vulnerability of indigenous people to receive health attention, in particular the most expensive ones.

\subsection{Principal Components}

The results of the method extract five principal components, and the first three components explain $60.7 \%$ of the total variance. The first principal component could be interpreted as a measure of general health condition, since it explains $29.7 \%$ of the total variance. The second principal component explains $16.3 \%$ 
and, together, the first two components account for $29.7 \%$ plus $16.3 \%$ or $45.9 \%$ of the total variance. The third component explains $14.7 \%$, and with the previous $45.9 \%$, it adds up to $60.7 \%$ of the total variance. The succeeding principal component has less variance, or explains less variation of the variables (Table 3 ).

The coefficients in Table 4 indicate the relative weighting of each variable in the component. The higher the absolute value of the coefficient, the more important the corresponding variable will be in the calculation of the component. In this study, the absolute value of a coefficient to be considered relevant is the value 0.5 .

In the first principal component, the highest coefficients correspond to the negative associations with deaths due to transmissible diseases, maternal, child and nutritional causes, and positive associations with immunizations against BCG, DPT, hepatitis, measles and polio, and also life expectancy. A second group includes families' out of pocket expenses, the number of hospital beds, and the coverage of immunization against tuberculosis (BCG). The interpretation of this component is primarily a measure of the main role that prevention plays in healthcare in Latin American countries, followed by the limits in providing secondary and tertiary services like enough hospital beds to receive patients and the need they have to invest their own money to cover hospitalization. In Donabedian's terms, the biological characteristics of immunology against several transmissible pathogenic are a main aspect of providing quality health services in Latin America, along with the number of hospital beds (although this material resource would be eventually financed by patients) (Table 4).

The second principal component has large positive associations with the percentage of cases of pneumonia attended by a health provider, the percentage of pregnant women with at least four visits for antenatal control and the average blood pressure, which is a proxy for access to health services for blood pressure

Table 3. Total variability explained in the principal component analysis.

\begin{tabular}{ccccccc}
\hline & $\begin{array}{c}\text { Initial } \\
\text { Eigenvalues }\end{array}$ & \% of Total Variance Explained & \multicolumn{3}{c}{$\begin{array}{c}\text { Extraction Sums of } \\
\text { Squared Loadings }\end{array}$} \\
\cline { 2 - 6 } & Total & \% of Variance & Cumulative \% & Total & \% of Variance & Cumulative \% \\
\hline 1 & 6.827 & 29.681 & 29.681 & 6.827 & 29.681 & 29.681 \\
2 & 3.740 & 16.261 & 45.942 & 3.740 & 16.261 & 45.942 \\
3 & 3.385 & 14.715 & 60.657 & 3.385 & 14.715 & 60.657 \\
4 & 1.784 & 7.757 & 68.414 & 1.784 & 7.757 & 68.414 \\
5 & 1.495 & 6.499 & 74.913 & 1.495 & 6.499 & 74.913 \\
6 & 1.322 & 5.749 & 80.662 & 1.322 & 5.749 & 80.662 \\
7 & 1.284 & 5.583 & 86.245 & 1.284 & 5.583 & 86.245 \\
8 & 0.846 & 3.678 & 89.923 & & & \\
9 & 0.729 & 3.170 & 93.093 & & & \\
\hline 10 & 0.429 & 1.865 & 94.959 & & & \\
\hline
\end{tabular}


Table 4. Principal component analysis of healthcare.

\begin{tabular}{|c|c|c|c|c|}
\hline Component Matrix & 1 & 2 & 3 & 4 \\
\hline BCG & -0.907 & 0.018 & -0.152 & 0.205 \\
\hline Polio & 0.902 & -0.139 & 0.208 & -0.076 \\
\hline Hepatitis & 0.893 & -0.135 & 0.331 & 0.083 \\
\hline DPT & 0.880 & -0.148 & 0.325 & 0.047 \\
\hline Measles & 0.846 & -0.173 & 0.388 & 0.057 \\
\hline Antenatal 4 visits & 0.720 & 0.199 & -0.419 & -0.081 \\
\hline Pneumonia treatment & 0.687 & -0.363 & -0.045 & 0.063 \\
\hline Blood pressure aver. & -0.580 & -0.309 & 0.492 & 0.094 \\
\hline Death by Transmissib. & 0.555 & 0.384 & -0.513 & 0.188 \\
\hline BK treatment & 0.532 & 0.205 & 0.240 & -0.276 \\
\hline BK coverage & -0.162 & 0.831 & 0.425 & 0.105 \\
\hline Diabetes & -0.243 & 0.822 & 0.460 & 0.135 \\
\hline Hospital Beds & -0.283 & 0.790 & 0.460 & 0.172 \\
\hline Physicians & 0.028 & -0.554 & 0.434 & 0.327 \\
\hline Homicides & -0.443 & -0.465 & 0.577 & 0.206 \\
\hline Death-Injuries & 0.242 & 0.033 & 0.554 & -0.252 \\
\hline Out of pocket & -0.174 & -0.150 & 0.539 & -0.370 \\
\hline Differential Access Ind. & 0.334 & 0.079 & 0.512 & 0.646 \\
\hline$\%$ Indigenas & 0.466 & 0.334 & -0.146 & 0.472 \\
\hline Esp. de Vida & -0.366 & -0.568 & -0.047 & 0.260 \\
\hline Gini & -0.159 & -0.428 & -0.152 & 0.420 \\
\hline Poverty & -0.003 & 0.166 & -0.071 & 0.230 \\
\hline Health expenditure & 0.215 & 0.084 & -0.420 & 0.498 \\
\hline
\end{tabular}

monitoring, and a second group of coefficients includes the negative associations with the percentage of poverty and the percentage of indigenous people in the total population. Therefore, this second component combines indicators that represent the negative social base where healthcare is provided unequally to the population and, at the same time, indicators that combine the availability of health services and positive patient behavior (such as attending to health services for monitoring pregnancy and blood pressure). This second component links apparently contradictory domains, such as the strong negative social base of inequality observed in Latin America-high levels of poverty and an indigenous population concentrated under the poverty line and with difficulty of access to health services and, at the same time, the willingness of this population to monitor and care for their health by attending health services, even if they are not equally available. It is important to observe that the poor and the indigenous population have much higher negative coefficients of participation in general 
health conditions than the positive behavior of the population, who are willing to monitor and care for their own health.

The third principal component includes as highest coefficients the percentage of deaths due to injury, the incidence of diabetes, the annual number of homicides and the Gini index of inequalities, representing the social base of disadvantages for healthcare combined with the life-styles or preferences towards taking risks, both in relation to diet-e.g. sugar consumption-and to tolerance to violence.

If we include the fourth component, besides increasing the total variance to explain healthcare provision to $68.4 \%$, the coefficient of Gini index of inequality reinforces the negative contribution of inequalities to the health conditions in Latin America.

\section{Discussion}

The first group of main principal components combines infrastructure-material and human resources-with biological characteristics. This result expresses the availability and quality of primary attention in healthcare. In a systematic way, prevention is the main result in healthcare in Latin America, since immunization is close to universal, and has allowed Latin American populations to extend their life expectancy. This achievement is due to the introduction and expansion of vaccines and other improvements in the infrastructures of water, sanitation, and health services in the region in the second half of the $20^{\text {th }}$ Century. In Donabedian's terms, the physical environment-mainly the expansion and actual availability of infrastructures and material resources available in the last 70 years -along with immunization, treatments against transmissible diseases and hospital beds, are the main mechanisms responsible for the main improvements in healthcare in Latin America.

The second group of principal components includes the availability of the secondary level of attention in healthcare. The expansion of this health supply allows the population to be committed to monitoring blood pressure, the health of pregnant women, and most other frequent health events, such as the cases of pneumonia attended by a health provider and pregnant women with at least four visits from antenatal control.

These improvements happen with the advantage of having diverse technological and scientific bases, in particular the coexistence of western and non-western bases of knowledge and care. The presence of a high number of or high proportion of both indigenous groups and indigenous medicine in several Latin American countries is positively combined with advances in biological characteristics, primary and secondary care, particularly in immunizations, in the control of transmissible diseases, and in the provision of antenatal care. Therefore, western and non-western medicines have co-existed and have contributed to improvements in healthcare, confirming that cultural diversity is not competing, but collaborating with Western medicine, according to Donabedian's framework. 
However, these achievements compete negatively with poverty and inequalities and with disadvantages for indigenous people. This group of principal components in healthcare indicates also the negative social base in which healthcare is provided unequally, in contradiction to the patients' positive behavior and willingness to monitor their main healthcare events and attending primary and secondary levels of care. In particular, the inequalities and disadvantages of indigenous people in accessing western medicine and services represent the negative social base where healthcare is provided, in spite of their cultural diversity and their willingness to monitor and care for their own health by attending health services. The poor and indigenous populations have much higher negative coefficients of participation in general health indicators, even considering their positive behavior of willingness to monitor and care for their own health. The indigenous disadvantage in healthcare access is a result of their structural poverty and inequalities, independently of their non-Western culture and medicine.

The third group of principal components in health care mainly includes populations' behaviors and preferences toward risks. In Latin America, the population is more exposed to social risks such as excesses in sugar consumption and tolerance to violence (measured as the incidence of diabetes, the ratio of deaths due to injury, and the annual number of homicides), in the same group with the Gini index of inequalities. It is important to consider that Latin America has the highest Gini index among all the regions in the world, and some of their metropolitan areas are among the ones with the highest homicide rates in the world. This component reinforces the social base of disadvantages for healthcare, related to attitudes and life-styles towards taking risks, for example, in relation to diet-e.g. sugar consumption - and to tolerance of violence.

These are additional and complex challenges for healthcare in Latin America, during a moment of demographic transition in which the population is composed of high proportions of youth and adults of productive ages, who are more exposed to violence and market pressures which encourage an increase in the consumption of high caloric and processed food, for example. These current risk behaviors and attitudes will impact their aging process, and is expected to occur within the next two decades. Risk behaviors, and preferences and life-styles in risk diet and violence, combined with structural inequalities and the historical exclusion of discriminated indigenous people would bring heavy consequences in next two decades, such as producing increasing rates of chronic diseases, aftermath and disabilities from early ages, and with high levels of dependency, high costs and demands for both families and health systems, and-quite possibly-decreases in life expectancy.

Finally, health assurance in Latin America is a result of three principal components that are associated; in the first place, with a set of immunizations and other material resources, such as the number of hospital beds. In second place, a set of primary and secondary care includes the prevention and successful treat- 
ment of pneumonia attended by a health provider, and the monitoring of pregnant women and their blood pressure, although these positive results are mitigated by the poverty and disadvantages of indigenous people, even considering the positive co-existence of western and non-western cultures. This second component links apparently contradictory domains, such as the strong negative social base of inequality observed in Latin America-high levels of poverty and an indigenous population concentrated below the poverty line and with difficulty of access to health services-and, at the same time, the willingness of this population to monitor and care for their own health by attending Western health services, even if they are not equally available. It is important to observe that the poor and the indigenous population have much higher negative coefficients of participation in general healthcare, due to the fact that, in general, indigenous are mostly extreme poor and live in rural areas, where health services are scarce or not available.

The third principal component includes diabetes, homicide rates and deaths due to injury associated to the Gini index of inequalities, reinforcing the role that this negative social base of disadvantages plays in healthcare, combined with life-styles or preferences towards taking risks, both in relation to diet-e.g. sugar consumption-and to tolerance to violence.

Moreover, achievements in extending immunizations programs, primary and secondary care, and the willingness of the population to monitor its health condition also depend on patients' financing, since out of pocket expenses are also included among the main determinants negatively affecting healthcare. In a scenario of poverty and inequality in the region with the highest multiculturalism in the world, it is relevant to consider the strong disadvantages and discrimination of indigenous people, since these out of pocket expenses means additional barriers for indigenous to continue improving their health conditions and, for the countries, to reduce gaps in healthcare performance.

Even after the recent decades of extension of health coverage and affirmative policies in most countries in Latin America, these structural disadvantages persist and need more incisive actions to promote equality and social justice. In particular it is relevant to develop and implement programs of health education, to promote changes in behaviors, attitudes and practices, and create incentives towards positive preferences and life-styles, values and attitudes against risk attitudes and behaviors.

The exclusion and discrimination of indigenous groups and of their cultures are additional obstacles to achieving the main objectives of health policies, which are the distribution and the efficient allocation of resources based on equity promotion and social justice. The technical and multicultural medicine and social base present in Latin America would receive incentives to recognize diversity, promote traditional healthy diets, and preventive behaviors and life-styles. The inclusion of these vulnerable groups and the recognition of their culture and non-Western values would contribute to the re-education of the non-indigenous 
towards anti-discriminatory behavior, and to take advantage of multiculturalism. Indigenous social disadvantages and gaps in health would be analyzed, as well as the recognition of their positive contributions in healthy diet, behaviors and culture, which can be brought to improve the health of the general population, to be identified.

Occidental medicine and the extension of health systems in Latin America have extended primary and secondary care leading to increasing average life expectancies. However, recommendations would be made to continue guaranteeing the successful results of preventive and curative basic services and, at the same time, to implement measures to reduce social inequalities in health. Some suggestions include adopting education in health and the promotion of changes in life-styles and behaviors, as well as adopting a culturally sensitive approach to include indigenous people through affirmative policies to reduce their disadvantages. This would reduce social and economic inequalities that create obstacles to achieving real universalization and a better quality of health.

There are already many barriers to accessing healthcare, both from the demand side, and on the supply side. The financial barrier that forces people to use out of pocket expenses to cover health needs is a significant barrier on the demand side, but also changes in behaviors and preferences toward risks should be an important and urgent objective of policies in health.

Therefore, integral actions would combine universal coverage beyond the limited discussion of universal access to health systems, since there are incentives from the market related to risk attitudes and behaviors, with increasing demand for new occidental medicines and healthcare technologies that compete for public investment made by the State in healthcare, particularly in hospitals and for more complex exams and treatments, or increasingly expensive health commodities.

The discussion on healthcare in Latin America would be more concentrated on the discussion of health needs, considering investments in education about populations' risk preferences and life-styles and, at the same time, reducing health inequalities, not only in access to health services, but also in the real capacity of the indigenous and poorest groups to pay for services or to contribute to pre-paid funds.

In this sense, new plans oriented to poor and indigenous people can be contradictory in a context of poverty, inequalities, vulnerabilities, discrimination, and the incapacity of several groups to pay for healthcare, either from their own pockets or through pre-paid plans.

The most important challenge in continuing to improve healthcare in Latin America is the reduction of inequalities while continuing to expand access and quality in public services and creating incentives for the poorest and for indigenous groups to successfully use western healthcare under equal conditions to other groups. These mechanisms would not be successful through charging the costs to the poorest population, since poverty is the negative framework under which healthcare is operating. At the same time, it would contribute to reducing 
inequalities and discrimination in order to study, value and exchange the possible advantages of non-western medicine, and the positive behaviors and life-styles of indigenous cultures that characterize the region.

\section{Conflicts of Interest}

The author declares no conflicts of interest regarding the publication of this paper.

\section{References}

[1] Mesa Lago, C. (1986) Comparative Study of the Development of Social Security in Latin America. International Social Security Review, 39, 127-133. https://doi.org/10.1111/j.1468-246X.1986.tb00625.x

[2] Mesa Lago, C. (1989) Financing and Attention in Health in Latin America and the Caribbean, with Focus on Social Security. Economic Development Institute (EDI) Seminar Paper, No. 42, World Bank Institute (WBI), Washington DC. http://documents.worldbank.org/curated/en/176841468743757977/Financiamientode-la-atencion-a-la-salud-en-America-Latina-y-el-Caribe-con-focalizacion-en-el-se guro-social

[3] Mesa Lago, C. (1992) Health Care for the Poor in Latin America and the Caribbean. Inter-American Foundation and Pan American Health Organization, PAHO Scientific Publication, No. 539, Washington DC.

[4] Almeida, C.M. (2005) Reform of the State and of the Health Sector in Latin America. In: Minayo, M.C.S. and Coimbra, C.E.A.J., Eds., Acting Critiques: Human and Social Sciences in Health in Latin America, FIOCRUZ, Rìo de Janeiro, 6-60.

[5] Londoño, J.L. and Frenk, J. (1997) Structural Pluralism: Towards an Innovative Model for Health System Reform in Latin America. Health Policy, 41, 1-36. https://doi.org/10.1016/S0168-8510(97)00010-9

[6] Paim, J., Travassos, C., Almeida, C., Bahia, L. and Macinko, J. (9779) The Brazilian Health System: History, Advances, and Challenges. The Lancet, 377, 1778-1797. https://doi.org/10.1016/S0140-6736(11)60054-8

[7] Fleury, A.S. (2001) Universal, Plural or Dual? Models and Challenges in Health Attention in Latin America. Interamerican Development Bank, Washington DC.

[8] Cavangero, E., Almeida, G., Seely, E.S. and Marinho, F. (2015) Setting the Context for Universal Health Coverage Reforms in Latin America and the Caribbean. In: Dmytraczenko, T. and Almeida, G., Eds., Toward Universal Health Coverage and Equity in Latin America and the Caribbean. Evidence from Selected Countries Tania Dmytraczenko and Gisele Almeida, Editors World Bank, Pan American Organization, World Health Organization, Chapter 3, 19-52. https://doi.org/10.1596/978-1-4648-0454-0_ch2

[9] Donabedian, A. (1980) Explorations in Quality Assessment and Monitoring Vol. 1. The Definition of Quality and Approaches to Its Assessment. Health Administration Press, Ann Arbor.

[10] Donabedian, A. (1988) The Quality of Care. How Can It Be Assessed? JAMA, 260, 1743-1748. https://doi.org/10.1001/jama.1988.03410120089033

[11] Donabedian Wu, J.K. (1994) Two Problems of Computer Mechanics Program System. In: Proceedings of Finite Element Analysis and CAD, Peking University Press, Beijing, 9-15. 
[12] Mitchell, P.H., Ferketich, S., Jennings, B.M., American Academy of Nursing Expert Panel on Quality Health Care (2007) Quality Health Outcomes Model. Nursing Scholarship, 30, 43-46. https://doi.org/10.1111/j.1547-5069.1998.tb01234.x

[13] WHO (2012) World Health Statistics. https://doi.org/10.22233/20412495.0819.1 https://www.who.int/whosis/whostat/EN_WHS09_Full.pdf?ua=1

[14] WHO (2009) Health Worldforce, Infrastructure, Health Medicines. World Health Statistics. https://www.who.int/whosis/whostat/EN_WHS09_Table6.pdf

[15] World Bank (2019) Data Indicators. https://data.worldbank.org/indicator

[16] Lanas, F., Serón, P. and Lanas, A. (2013) Global Heart. Coronary Heart Disease and Risk Factors in Latin America. Global Heart, 8, 341-348. https://doi.org/10.1016/j.gheart.2013.11.005

[17] Duterman, G.H. (1989) Principal Components Analysis. Series Quantitative Applications in the Social Sciences. Sage University Papers, Indore. 


\section{Annex}

Table A1. Summary of analyzed literatures.

\begin{tabular}{|c|c|c|}
\hline Session & Key words & Literature \\
\hline Theoretic \& & Health care & Donabedian, A. (1980) Explorations in Quality Assessment and Monitoring Vol. 1. The \\
\hline Conceptual & & Definition of Quality and Approaches to Its Assessment. Health Administration Press, \\
\hline \multirow[t]{4}{*}{ Framework } & Coverage and quality & Ann Arbor. \\
\hline & \multirow{2}{*}{$\begin{array}{l}\text { Patient's biological } \\
\text { characteristics, behaviors } \\
\text { and preferences }\end{array}$} & $\begin{array}{l}\text { Donabedian, A. (1988) The Quality of Care. How Can It Be Assessed? JAMA, 260, } \\
\text { 1743-1748. }\end{array}$ \\
\hline & & $\begin{array}{l}\text { Donabedian Wu, J.K. (1994) Two Problems of Computer Mechanics Program System. In: } \\
\text { Proceedings of Finite Element Analysis and CAD, Peking University Press, Beijing, 9-15. }\end{array}$ \\
\hline & Non-western medicine & $\begin{array}{l}\text { Mitchell, P.H., Ferketich, S., Jennings, B.M., American Academy of Nursing Expert Panel } \\
\text { on Quality Health Care (2007) Quality Health Outcomes Model. Nursing Scholarship, 30, } \\
\text { 43-46. }\end{array}$ \\
\hline \multirow[t]{5}{*}{$\begin{array}{l}\text { Context of } \\
\text { Latin America }\end{array}$} & Latin America & $\begin{array}{l}\text { Almeida, C.M. (2005) Reform of the State and of the Health Sector in Latin America. In: } \\
\text { Minayo, M.C.S. and Coimbra, C.E.A.J., Eds., Acting Critiques. Human and Social Sciences } \\
\text { in Health in Latin America, FIOCRUZ, Rì de Janeiro. }\end{array}$ \\
\hline & Colombia & $\begin{array}{l}\text { Londoño, J.L. and Frenk, J. (1997) Structural Pluralism: Towards an Innovative Model for } \\
\text { Health System Reform in Latin America. Health Policy, 41, 1-36. }\end{array}$ \\
\hline & Brazil & $\begin{array}{l}\text { Paim, J., Travassos, C., Almeida, C., Bahia, L. and Macinko, J. (9779) The Brazilian Health } \\
\text { System: History, Advances, and Challenges. The Lancet, 377, 1778-1797. }\end{array}$ \\
\hline & Brazil & $\begin{array}{l}\text { Fleury, A.S. (2001) Universal, Plural or Dual? Models and Challenges in Health Attention } \\
\text { in Latin America. Interamerican Development Bank, Washington DC. }\end{array}$ \\
\hline & Latin America & $\begin{array}{l}\text { Cavangero, E., Almeida, G., Seely, E.S. and Marinho, F. (2015) Setting the Context for } \\
\text { Universal Health Coverage Reforms in Latin America and the Caribbean. In: } \\
\text { Dmytraczenko, T. and Almeida, G., Eds., Toward Universal Health Coverage and Equity } \\
\text { in Latin America and the Caribbean. Evidence from Selected Countries Tania } \\
\text { Dmytraczenko and Gisele Almeida, Editors World Bank, Pan American Organization, } \\
\text { World Health Organization, Chapter 3, 19-52. }\end{array}$ \\
\hline Method & $\begin{array}{l}\text { Correlations \& } \\
\text { Principal Components }\end{array}$ & $\begin{array}{l}\text { Duterman, G.H. (1989) Principal Components Analysis. Series Quantitative Applications } \\
\text { in the Social Sciences. Sage University Papers, Indore. }\end{array}$ \\
\hline \multirow[t]{3}{*}{ Data } & WHO & WHO (2012) World Health Statistics. \\
\hline & & WHO (2009) Health Worldforce, Infrastructure, Health Medicines. World Health Statistics. \\
\hline & World Bank & World Bank (2019) Data Indicators. \\
\hline
\end{tabular}

